\title{
Stable but Progressive Nature of Heart Failure: Considerations for Primary Care Physicians
}

\author{
Inder Anand ${ }^{1,2}$
}

Published online: 14 May 2018

(C) The Author(s) 2018

\begin{abstract}
Primary care physicians play a significant role in managing heart failure (HF), with the goals of reducing mortality, avoiding hospitalization, and improving patients' quality of life. Most HF-related hospitalizations and deaths occur in patients with New York Heart Association functional class II or III, many of whom are perceived to have stable disease, which often progresses without clinical symptoms due to underlying deleterious effects of neurohormonal imbalance and endothelial dysfunction. Management includes lifestyle changes and stepped pharmacological therapy directed at the four stages of HF, with aggressive uptitration of therapies, including betablockers and inhibitors of the renin-angiotensin-aldosterone system. Recently, two new HF treatments have become available in clinical practice. Ivabradine was approved to reduce the risk of hospitalization for $\mathrm{HF}$ in patients with stable, symptomatic HF. Additionally, the angiotensin receptor-neprilysin inhibitor (ARNI), sacubitril/valsartan, was found to be significantly superior to enalapril in reducing risks of cardiovascular death and HF-related hospitalization. The respective 2016 and 2017 American College of Cardiology/American Heart Association/Heart Failure Society of America clinical practice guideline updates recommend that patients taking angiotensin-converting enzyme inhibitor/angiotensin receptor blocker therapy be switched to ARNI therapy to further reduce morbidity and mortality. For HF management to be
\end{abstract}

Inder Anand

anand001@umn.edu

1 Cardiovascular Division, University of Minnesota Medical School, Minneapolis, MN 55455, USA

2 VA Medical Center, One Veterans Dr., Minneapolis, MN 55417, USA maximally effective, physicians must be knowledgeable about the risks and benefits of treatments and stay engaged with patients to identify signs of disease progression. This article provides an overview of the progressive nature of HF in apparently stable patients and describes areas for treatment improvement that may help to optimize patient care.

\section{Key Points}

Recent data have highlighted how considerable further improvement in outcomes in apparently stable patients with heart failure (HF) is possible if primary care physicians (PCPs) optimize delivery of care.

Although no simple means exist for PCPs to predict when a seemingly stable patient will decompensate, use of novel pharmacological agents may prevent the progression of HF.

This article outlines HF-management recommendations for PCPs, with a focus on patients with stable but progressive disease.

\section{Introduction}

Heart failure (HF) is a clinical syndrome caused by structural or functional abnormalities of the heart, resulting in a reduction in cardiac output or elevation of ventricular filling pressures at rest or during exercise. The major manifestations of HF are breathlessness, decreased exercise tolerance, and fatigue, which may be accompanied by signs 
of fluid retention, including peripheral edema, elevated jugular venous pressure, and crackles in the lungs.

The prevalence of HF increases with age [1]. However, in the last several decades, advances in HF treatment have led to improvements in survival, both in clinical trials and in the community [2-4]. These decreases in mortality extend to very elderly patients (aged $>80$ years) who have been hospitalized for HF [5].

Primary care physicians (PCPs) play an important role in improving outcomes in patients with HF, principally by implementing guideline-directed evaluation and management (GDEM) shown to reduce the risks of mortality and HF hospitalization $[2,3]$. In addition, PCPs play an active role in preventing HF-related hospital readmissions in accordance with the US Affordable Care Act's Hospital Readmission Reduction Program, which penalizes hospitals with above-average 30-day readmission rates for Medicare patients [6].

Despite recent improvements in mortality rates among patients with HF, the 5-year survival rates remain at about $50 \%$ [7]. Furthermore, as the US population ages, the healthcare burden of HF is expected to increase dramatically. Data from a 2015 report noted that HF affects more than 5 million Americans, and annual healthcare costs are more than \$US30 billion [7]. By 2030, an estimated 8.5 million adults in the USA will have HF, with annual costs of $\$$ US70 billion [7, 8]. Thus, significant treatment advances are needed to further improve outcomes. Improvements in management are especially needed for the large population of patients with New York Heart Association (NYHA) class II or III functional status, the largest population of patients with HF. These patients are often perceived to have more stable disease. However, sudden cardiac death remains the leading cause of mortality in these patients, and they account for the majority of HFrelated hospitalizations and deaths [9].

Given their increasing role in managing HF, PCPs are in a position to work with patients to improve clinical outcomes. Recent data have highlighted how considerable further improvement in outcomes in apparently stable patients with HF is possible if PCPs optimize their care. This article outlines management recommendations, with a focus on patients with stable but progressive HF.

\subsection{Classification and Management of the Stages of $\mathbf{H F}$}

Historically, HF was dichotomized based on measurement of the left ventricular (LV) ejection fraction (EF) $[2,10]$. Patients with LVEF $\geq 50 \%$ were considered to have HF with normal or preserved EF (HFpEF) and those with LVEF $\leq 40 \%$, HF with reduced EF (HFrEF) $[2,10]$. This left patients with an LVEF in the range of $40-49 \%$ in a "grey area," which has been varyingly defined [10]. Most recently, the 2016 European Society of Cardiology HF guidelines defined such patients as having HF with midrange $\mathrm{EF}$ (HFmrEF) [10]. However-as discussed later in this article-for the sake of management, patients with HFpEF and HFmrEF are considered collectively. Epidemiological studies suggest that approximately $50 \%$ of the total HF population have HFrEF and the remainder have HFpEF and HFmrEF [2, 11]. Therapeutic strategies for the management of HF differ based on EF classification because the response to therapy varies between the two groups [2]. Moreover, recommendations for the use of pharmacological GDEM have been more extensively developed for HFrEF than for HFpEF, because clinical trials have demonstrated benefits with such therapies in patients with HFrEF but not in patients with HFpEF [12]. As such, this review focuses primarily on HFrEF management. GDEM for patients with HFpEF focuses primarily on managing symptoms and addressing risk factors and comorbidities for disease progression [2].

In 2009, the American College of Cardiology (ACC)/ American Heart Association (AHA) further classified HF into stages that emphasized the progressive nature of the disease, from risk factors to development of structural heart disease. The stages complement the NYHA functional classifications that focus on limitation of exercise capacity and the symptomatic status of the patient. At each stage of the new classification, management is aimed at preventing the development of the next stage.

Stage A patients have risk factors for the development of HF but do not have structural or functional heart disease and are asymptomatic. Management of risk factors prevents the development of HF in patients at this stage. For example, long-term treatment of hypertension has been shown to reduce the risk of developing HF by approximately 50\% [2,13-17]. Similarly, treatment of hyperlipidemia with statin therapy reduces the risk of developing cardiovascular disease (CVD), including HF [18]. In addition, insulin resistance has been shown to increase the risk of developing HF [19-23], and glycated hemoglobin $\left(\mathrm{HbA}_{1 \mathrm{c}}\right)$ concentration $\geq 10.5 \%$ was associated with increased risk for developing $\mathrm{HF}$ compared with $\mathrm{HbA}_{1 \mathrm{c}}$ concentration $<6.5 \%$ [hazard ratio (HR) 3.98 ; 95\% confidence interval (CI) 2.23-7.14] [22]. Although hyperglycemia contributes to the development of $\mathrm{HF}$, its treatment as a risk factor for CVD has been controversial because some hypoglycemic medications have been shown to increase the risk of cardiovascular events [24]; however, recent data indicate that sodium-glucose cotransporter-2 (SGLT2) inhibitors reduced the rate of cardiovascular outcomes, including HF, and may be considered to treat hyperglycemia in patients at high risk of CVD [25]. In particular, an analysis of data from the EMPA-REG 
OUTCOMES (Empagliflozin, Cardiovascular Outcomes, and Mortality in Type 2 Diabetes; ClinicalTrials.gov number, NCT01131676) trial has shown that empagliflozin, an SGLT2 inhibitor, is associated with a reduced risk for HF-related hospitalization or death compared with placebo (HR $0.61 ; 95 \%$ CI $0.47-0.79 ; P<0.001$ ) [26]. Thus, the effective management of these risk factors received a recommendation [class of recommendation (COR) I, level of evidence (LOE) A] to prevent the development of HF [2]. Both pharmacological treatments, such as SGLT2 inhibitors for patients with diabetes mellitus, and lifestyle modifications, including sodium restriction in patients with hypertension, are appropriate strategies to reduce the risk of developing $\mathrm{HF}$ at this stage [2].

Stage B patients are those who have already developed structural heart disease, such as myocardial infarction, LV dysfunction or LV hypertrophy, but are asymptomatic [2]. These stage B patients with asymptomatic LV dysfunction (ASLVD) are at an increased risk of experiencing a CV event (HR 3.32; 95\% CI 1.98-5.58; $P<0.0001$ ) and mortality (HR 3.47; 95\% CI 2.03-5.94; $P<0.0001$ ) [27]. To reduce the risk of morbidity and mortality and prevent progression to symptomatic HF in patients with ASLVD, the ACC Foundation (ACCF)/AHA Guideline for the Management of Heart Failure provides a class I (LOE A) recommendation for the use of the angiotensin-converting enzyme inhibitor (ACEI) enalapril [2]. This recommendation is based on the results of the SOLVD (Studies of Left Ventricular Dysfunction) prevention trial, which reported that treatment with enalapril compared with placebo reduced the risk of death or hospitalization for congestive HF by $20 \%$ (95\% CI 9-30; $P<0.001$ ) [28]. Furthermore, an analysis of the 15-year post-trial follow-up data found that the beneficial effects of initial randomization to enalapril therapy, compared with placebo, continued to be seen throughout this period, with an overall absolute mortality risk reduction (ARR) of $6.5 \%(P=0.01)$ [29]. These results underscore the importance of the early initiation of therapy and suggest that delaying treatment in patients with LV systolic dysfunction increases their risk of morbidity and mortality. Finally, myocardial revascularization to correct ischemia has been shown to be associated with better clinical prognosis $[30,31]$. Screening with noninvasive imaging to detect myocardial ischemia is recommended for patients with new-onset HFrEF and coronary artery disease without angina, unless the patient is not eligible for revascularization of any kind (COR IIA, LOE C) [2].

Stage C patients have structural heart disease with prior or current symptoms of HF [2]. Before the recent approval of the two new HF therapies, ivabradine and sacubitril/valsartan, the 2013 ACCF/AHA guidelines recommended that patients with stage $\mathrm{C}$ HFrEF receive GDEM, in addition to management of comorbidities, to reduce their risk of disease progression (COR I, LOE A) [2]. The mainstay of GDEM for patients with stage $\mathrm{C}$ disease at that time included the use of recommended doses of ACEIand if not tolerated, angiotensin receptor blocker (ARB) therapy (COR I, LOE A) —along with adequate doses of beta-blocker therapy with bisoprolol, carvedilol, or sustained-release metoprolol succinate (COR I, LOE A) to reduce the risk of morbidity and mortality [2]. To further reduce morbidity and mortality, aldosterone receptor antagonists are recommended (COR I, LOE A) on top of ACEI/ARB and beta-blocker therapy in patients with NYHA class II-IV HFrEF, provided adequate renal function and potassium concentration $<5 \mathrm{mEq} / \mathrm{dl}$ [2]. In symptomatic African American patients with NYHA class III-IV HFrEF already receiving optimal doses of ACEI/ ARB and beta-blocker therapy, the combination of hydralazine and isosorbide dinitrate is recommended (COR I, LOE A) to further reduce morbidity and mortality [2]. Although loop diuretics have not been shown to reduce mortality, they may be initiated in patients with NYHA class II-IV to reduce volume overload (COR I, LOE C) [2].

Digoxin is a third-line treatment for $\mathrm{HF}$, usually restricted as an add-on therapy to GDEM (COR IIA, LOE B) in patients with NYHA class III or IV HFrEF who remain symptomatic, to reduce the risk of hospitalization [2]. In addition, digoxin is often used in patients with atrial fibrillation to achieve rate control as an adjunct to betablockers [2]. However, physicians should be aware that digoxin toxicity may occur (1) with high doses (0.375-0.50 mg daily) [32, 33]; (2) in patients with coexisting hypokalemia, hypomagnesemia, or hypothyroidism [34, 35]; and (3) with the concomitant use of drugs that increase digoxin serum concentrations [36-38]. To prevent toxicity, concomitant drug interactions and comorbidities should be considered upon digoxin initiation, and patients should be continually monitored [2, 39].

Two types of devices are available for patients with stage $\mathrm{C}$ HFrEF [2]. Implantable cardioverter-defibrillator (ICD) therapy is recommended (COR I, LOE A) for the primary prevention of sudden cardiac death in patients with NYHA class II-III HFrEF receiving GDEM who have either ischemic cardiomyopathy at least 40 days postmyocardial infarction or nonischemic dilated cardiomyopathy and a life expectancy over 1 year [2]. Cardiac resynchronization therapy (CRT) is recommended for NYHA class II, III, or ambulatory NYHA class IV HFrEF (COR I, LOE A for NYHA class III/IV; LOE B for NYHA class II) patients receiving GDEM who are in sinus rhythm with a left bundle-branch block and a QRS duration of $\geq 150 \mathrm{~ms}$ [2].

Stage D patients have advanced end-stage refractory HF and remain persistently symptomatic despite maximum pharmacological and device therapies [2]. These patients 
Table 1 Estimated potential impact of optimal implementation of GDEM [45, 46]

\begin{tabular}{lcl}
\hline $\begin{array}{l}\text { Pharmacologic class of } \\
\text { GDEM }\end{array}$ & $\begin{array}{l}\text { Current HF population eligible for therapy and } \\
\text { untreated }^{\text {a }}\end{array}$ & $\begin{array}{l}\text { Potential deaths prevented per year with optimal implementation } \\
\text { of }^{\text {therapy }}{ }^{\mathrm{a}}\end{array}$ \\
\hline ACEI/ARB [45] & $501,767(20.4)$ & $6516(9.6)$ \\
Beta-blocker [45] & $361,809(14.4)$ & $12,922(19)$ \\
Aldosterone antagonist & $385,326(63.9)$ & $21,407(31.5)$ \\
$\quad$ [45] & $139,749(92.7)$ & $6655(9.8)$ \\
Hydralazine/nitrate [45] & $199,604(61.2)$ & $8317(12.2)$ \\
CRT [45] & $852,512(49.4)$ & $12,179(17.9)$ \\
ICD [45] & $2,287,296$ eligible $\left.^{\mathrm{b}}\right)$ & 28,484 \\
ARNI [46] &
\end{tabular}

$A C E I$ angiotensin-converting enzyme inhibitor, $A R B$ angiotensin receptor blocker, $A R N I$ angiotensin receptor-neprilysin inhibitor, $C R T$ cardiac resynchronization therapy, GDEM guideline-directed evaluation and management, $H F$ heart failure, $H F r E F$ heart failure with reduced ejection fraction, ICD implantable cardioverter defibrillator

${ }^{a}$ Data are presented as $n(\%)$. Estimates are based on the number of patients with HFrEF in the USA (drawn from the 2010 American Heart Association Heart Disease and Stroke Statistics Update) and the number of patients with HFrEF who are potentially eligible for each of the guideline-recommended $\mathrm{HF}$ therapies (drawn from published $\mathrm{HF}$ registries)

${ }^{\mathrm{b}}$ Estimated number of patients with HFrEF who are eligible for ARNI therapy

need to be referred to advanced HF centers for specialized treatment strategies, such as insertion of mechanical circulatory assist devices and consideration of cardiac transplantation or end-of-life care [2].

Many of the medications commonly prescribed in patients with $\mathrm{HF}$, including antiarrhythmic drugs, nonsteroidal anti-inflammatory drugs, and thiazolidinediones, have been shown to potentially worsen HF [2]. These should be avoided and discontinued whenever possible (COR III, LOE B) [2]. Calcium channel-blocking drugs (other than amlodipine and felodipine) should not be used to treat patients with HFrEF (COR III, LOE A) because they may worsen outcomes for these patients [40-44]. Additionally, the long-term use of infused positive inotropic drugs should be avoided in patients with HFrEF, except when used as palliation (COR III, LOE C), because they may worsen HF or precipitate death [2].

Although GDEM improves patient outcomes, physician adherence to clinical practice guideline recommendations is suboptimal [45]. For example, renin-angiotensinaldosterone system (RAAS) blockers are recommended to reduce the risk of mortality and hospitalization in patients with HF [2], but these drugs are underutilized [45]. Optimal implementation of GDEM has the potential to prevent thousands of deaths each year based on estimates from Fonarow and colleagues (Table 1) [45, 46].

\subsection{Patient Monitoring and Management of Fluid Retention}

At each patient encounter, vital signs and volume status should be evaluated, including patient weight, jugular venous pressure, peripheral edema, and orthopnea (COR I,
LOE B) [2]. For patients with HFrEF who have evidence of fluid retention, diuretic therapy is recommended in addition to GDEM for symptomatic management, unless contraindicated (COR I, LOE C) [2]. Loop diuretics should be initiated at low doses and uptitrated until weight decreases by $0.5-1.0 \mathrm{~kg}$ daily [2]. Twice-daily administration may be employed to sustain these effects, if necessary. For patients who are resistant to diuretics, intravenous administration or combination with different diuretic classes may be considered [2].

Because of the risk for electrolyte disturbances, azotemia, and hypotension with diuretics, aldosterone antagonists, ACEIs, and ARBs, it is recommended that renal function and serum electrolytes should be monitored within 2 weeks of initiating or modifying therapy and periodically thereafter (COR I, LOE C) [2]. Serial measurement of natriuretic peptide concentrations for the purpose of improving patient outcomes is not recommended because supporting evidence is lacking [47].

\subsection{Subclinical Progression in Stable HF}

Patients with stable HF typically experience subtle disease progression that is often not clinically detectable. Even when patients are receiving GDEM, considerable cardiac damage and progression of HF can occur over time as a result of continued deleterious effects of activated RAAS and sympathetic nervous system pathways as well as inadequate effects of endogenous compensatory peptides (e.g., natriuretic peptides, bradykinin) [48]. For example, many patients with clinically stable HF have elevated cardiac troponin $\mathrm{T}$ concentrations, suggesting continuous underlying cardiac myocyte injury [49]. Elevated troponin 
Table 2 Characteristics of patients with advanced HF [2]

Repeated $(\geq 2$ ) hospitalizations or emergency department visits for HF in the past year

Progressive deterioration in renal function

Weight loss without other cause

Intolerance to ACEIs due to hypotension and/or worsening renal function

Intolerance to beta-blockers due to worsening $\mathrm{HF}$ or hypotension

Frequent systolic blood pressure of $<90 \mathrm{mmHg}$

Persistent dyspnea with dressing or bathing, requiring rest

Inability to walk one block on level ground due to dyspnea or fatigue

Recent need to escalate diuretics to maintain volume status, often reaching daily furosemide-equivalent dose of $>160 \mathrm{mg} / \mathrm{day}$ and/or use of supplemental metolazone therapy

Progressive decline in serum sodium, usually to $<133 \mathrm{mEq} / 1$

Frequent implantable cardioverter-defibrillator shocks

$A C E I$ angiotensin-converting enzyme inhibitor, $H F$ heart failure

concentrations in patients with stable HF are associated with increased risk of cardiovascular mortality and morbidity [49, 50]. Disease progression can also occur as a result of prolonged endothelial dysfunction and alterations in the nitric oxide pathway, which promote increased vascular stiffness, myocardial damage, and vascular remodeling [51].

Table 2 summarizes some clinical characteristics of patients with advanced HF that indicate clinically obvious disease progression [2]. For example, weight loss without other causes may indicate cardiac cachexia, which is associated with poor prognosis [52]. Although these features of disease progression are often clear in patients with advanced HF, predicting which clinically stable patients may decompensate is challenging. This difficulty is highlighted by studies such as PARADIGM-HF (Prospective Comparison of ARNI (angiotensin receptor-neprilysin inhibitor) with ACEI to Determine Impact on Global Mortality and Morbidity in Heart Failure; NCT01035255), in which $26.5 \%$ of patients with apparently stable HF who received standard-of-care therapy, including enalapril, experienced a primary event of cardiovascular death or first hospitalization for worsening HF (WHF) during the trial (median duration of follow-up, 27 months) [53]. Indeed, no simple means exist for physicians to predict when a seemingly stable patient will decompensate. Thus, it is important for physicians to remain aware of the significant risks associated with all stages of $\mathrm{HF}$ and to recognize therapies that may improve the underlying pathophysiology of HF for patients with stable yet progressive disease.

\section{Potential Impact of New Therapies}

Two new therapies have the potential to improve outcomes for patients with stable, symptomatic HF [47]. In April 2015 , ivabradine became the first new medication in nearly a decade to be approved by the US FDA for the treatment of chronic HF [54]; in July 2015, the FDA also approved the ARNI sacubitril/valsartan for the same condition [55].

\subsection{Ivabradine}

Ivabradine is a specific inhibitor of the hyperpolarizationactivated cyclic nucleotide-gated channel, which is responsible for diastolic depolarization of pacemaker cells in the sinoatrial node [56]. Ivabradine is therefore a pure heart-rate-reducing agent with no other cardiovascular effects, indicated to reduce the risk of hospitalization for WHF [56]. The approval of ivabradine was based on results of the randomized, double-blind SHIFT (Systolic Heart Failure Treatment With the $I_{\mathrm{f}}$ Inhibitor Ivabradine Trial; NCT02441218) that compared ivabradine versus placebo in 6558 patients with symptomatic HFrEF [56, 57]. Eligible patients were required to have stable, symptomatic HF with a baseline EF of $\leq 35 \%$; to be in sinus rhythm with a resting heart rate of at least 70 beats per minute (bpm); to have been hospitalized for HF within the last year; and to be receiving stable background treatment, including a betablocker, at the maximally tolerated dose or have a contraindication to beta-blocker use $[56,57]$. Over a median follow-up period of 22.9 months, significantly fewer patients in the ivabradine group [793/3268 (24\%)] than in the placebo group [937/3290 (29\%)] experienced the primary endpoint of cardiovascular death or hospitalization for WHF (HR 0.82; 95\% CI 0.75-0.90; $P<0.001$ ) [57]. The effects were primarily driven by hospital admissions for WHF [672 (21\%) placebo vs. 514 (16\%) ivabradine; HR $0.74 ; 95 \%$ CI $0.66-0.83 ; P<0.0001]$ and deaths due to $\mathrm{HF}[151(5 \%)$ vs. $113(3 \%) ; \mathrm{HR} \quad 0.74 ; 95 \%$ CI $0.58-0.94 ; P=0.014$ ] [57]. Overall, findings from SHIFT indicated that heart rate reduction has the potential to improve clinical outcomes for patients with stable, chronic HF [57]. However, ivabradine has been shown to increase 
the risk of atrial fibrillation [56, 57]. It should be used only in patients with normal sinus rhythm and discontinued if patients develop atrial fibrillation [56, 57].

\subsection{Sacubitril/Valsartan}

Sacubitril/valsartan is a novel, first-in-class drug that combines a neprilysin inhibitor with an ARB [58, 59]. Sacubitril is a prodrug that is metabolized to LBQ657, which inhibits neprilysin endopeptidase. Neprilysin inhibition prevents the degradation of B-type natriuretic peptide (BNP) and other compensatory peptides (e.g., bradykinin, adrenomedullin), thus increasing plasma levels of these peptides and enhancing their beneficial effects, which include vasodilation, natriuresis, diuresis, and inhibition of pathogenic growth and fibrosis [58, 59]. Valsartan counterbalances the increase of angiotensin II that also results from neprilysin inhibition, while simultaneously exerting the beneficial effects of ARBs seen in previous HF trials [60]. Unlike previous neprilysin inhibitors, such as omapatrilat, ARNI therapy does not inhibit angiotensinconverting enzyme, which allows for the degradation of bradykinin and thus lowers the risk for angioedema [60].

In the PARADIGM-HF trial, the safety and efficacy of sacubitril/valsartan were compared with that of enalapril, the standard-of-care ACEI shown to reduce mortality in patients with chronic HFrEF [53, 59]. The mean dose $(18.9 \mathrm{mg} /$ day $)$ of enalapril used in this trial was the highest dose achieved in any of the large outcome trials [53]. This randomized, double-blind, phase III trial enrolled 8442 patients with stable HFrEF (EF $\leq 40 \%$ ) and NYHA class II, III, or IV functional status who were receiving adequate doses of current standard-of-care HF medications, including an ACEI or ARB, beta-blockers, and mineralocorticoid antagonists [53]. Patients were randomly assigned 1:1 to receive enalapril $10 \mathrm{mg}$ twice daily or sacubitril/valsartan $200 \mathrm{mg}$ twice daily in addition to comprehensive concomitant background HF therapy. Patients were followed for a median of 27 months. Evaluation of the primary endpoint showed that, compared with enalapril, use of sacubitril/valsartan was associated with a $20 \%$ reduction in the composite of cardiovascular death or first hospitalization for HF (HR $0.80 ; 95 \%$ CI $0.73-0.87 ; P<0.001$ ), a $16 \%$ reduction in death from any cause (HR $0.84 ; 95 \%$ CI $0.76-0.93 ; P<0.001$ ), and significant improvements in HF symptoms and physical limitations as measured by the Kansas City Cardiomyopathy Questionnaire (betweengroup difference $1.64 ; 95 \%$ CI $0.63-2.65 ; P=0.001$ ) [53]. Additionally, sudden cardiac death was significantly reduced with sacubitril/valsartan compared with enalapril (HR 0.80; 95\% CI 0.68-0.94; $P=0.008$ ) [61]. Sacubitril/valsartan was generally well tolerated; the adverse events hypotension and nonserious angioedema were more common with sacubitril/valsartan, whereas renal impairment, hyperkalemia, and cough were more common with enalapril [53]. Significantly fewer patients in the sacubitril/valsartan group stopped treatment because of renal impairment compared with the enalapril group (0.7 vs. $1.4 \% ; P=0.002)$ [53].

As mentioned, one in four patients in the control group of PARADIGM-HF trial receiving GDEM had a primary clinical event (cardiovascular death or HF hospitalization) [53]. Thus, these apparently stable patients receiving adequate treatment remained at a high risk for serious adverse clinical outcomes. The benefit of sacubitril/valsartan was observed in these stable patients $(75 \%$ of patients randomized to treatment had NYHA class I or II functional status). The beneficial effects of sacubitril/valsartan compared with enalapril were consistent across all subgroups, regardless of patient baseline demographics and clinical characteristics [e.g., age, sex, ethnicity, geographic region, NYHA class, comorbidities, EF, N-terminal pro-BNP (NTproBNP) level, HF treatment history, or hospitalization history] [53]. Moreover, a recent analysis showed that optimal implementation of ARNI therapy in the appropriate community-based population of patients with NHYA class II-III HFrEF who tolerate ACEI/ARB therapy would prevent approximately 28,000 deaths per year [46].

A separate analysis of data from the PARADIGM-HF trial performed in surviving patients showed that those who received sacubitril/valsartan were significantly less likely to require intensification of HF treatment $(P=0.003)$ or emergency-department treatment for WHF $(P=0.001)$ than patients who received enalapril [62]. Patients treated with sacubitril/valsartan were also less likely to have WHF requiring the addition of a new drug, intravenous therapy, or an increase in the daily dose of diuretic for $>1$ month $(P=0.003)$; to be evaluated and treated for WHF in the emergency department but discharged without hospital admission $(P=0.001)$; to be hospitalized for WHF $(P<0.001)$; to be hospitalized for any reason $(P<0.001)$; to be hospitalized for HF more than once $(P=0.001)$; to receive intravenous inotropic agents $(P<0.001)$; to require intensive care $(P=0.019)$; or to require HF device implantation or heart transplantation $(P=0.07)$ [62]. In these patients, sacubitril/valsartan treatment was associated with lower levels of NT-proBNP and troponin, which are biomarkers for myocardial wall stress and injury, than was enalapril [62].

\subsection{Guideline Update}

The remarkable results of the SHIFT and PARADIGM-HF trials led the ACC/AHA/Heart Failure Society of America (HFSA) to release an update to the guideline for the management of HF in May 2016 [4]. The recommendations 
provided in the 2016 guideline update have been carried over to the most recent 2017 guideline update [47]. The guideline recommended that ivabradine "can be beneficial to reduce HF hospitalization for patients with symptomatic (NYHA class II, III) stable chronic HFrEF (LVEF $\leq 35 \%$ ) who are receiving GDEM, including a beta-blocker at the maximum-tolerated dose, and who are in sinus rhythm with a heart rate of $70 \mathrm{bpm}$ or greater at rest" (COR IIA, LOE B-R) $[4,47]$. The update noted that only $25 \%$ of patients in the trial were receiving optimal doses of beta-blocker therapy and encouraged efforts to maximize the use of these agents in this setting. The second specific recommendation in the update related to the ARNI class of drugs, of which only sacubitril/valsartan is currently available and approved $[4,47]$. The update added the ARNI class to an existing recommendation (alongside ACEIs or ARBs) for a management strategy to reduce morbidity and mortality in patients with chronic HFrEF (COR I, LOE B-R) [4, 47]. It specifically noted that patients with chronic, symptomatic HFrEF who have NYHA class II or III disease should be switched from an ACEI or ARB to the ARNI, sacubitril/valsartan, to further reduce morbidity and mortality (COR I, LOE B-R) [46, 47]. This particular recommendation represents a clear departure from the previous guideline that only recommended adding newly approved drugs to existing standard-of-care therapy and never recommended switching one class of therapy for another.

It is important to point out that the American Academy of Family Physicians (AAFP) has not completely endorsed these guideline recommendations because of concerns that sacubitril/valsartan was tested only in one study and that postmarketing data in the American population on potential harm and adverse side effects are limited [63]. However, it should be emphasized that the patients enrolled in the PARADIGM-HF trial from the USA were typical of patients seen in primary care practice: Approximately 26\% were African American and nearly 60\% had an ICD [64]. In patients from the USA, a somewhat greater beneficial effect with sacubitril/valsartan compared with enalapril on the primary outcome was observed (HR $0.66 ; 95 \%$ CI 0.47-0.92) compared with that of the entire cohort (HR 0.80 ; 95\% CI 0.73-0.87) [64]. Similar patient characteristics and outcomes were observed in the prespecified subgroup analyses for North America (including both Canada and the USA); $54 \%$ of these patients had an ICD, $19 \%$ were Black, and a somewhat greater beneficial effect with sacubitril/valsartan compared with enalapril on the primary outcome was observed (HR $0.67 ; 95 \%$ CI $0.50-0.90$ ) compared with that of the entire cohort (HR 0.80; 95\% CI 0.73-0.87) sacubitril/valsartan [65]. Because the evidence for the $20 \%$ reduction in the primary endpoint $(P<0.001)$ and for the $20 \%$ lower risk of cardiovascular death $(P<0.001)$ with sacubitril/valsartan compared with enalapril was very strong [53], randomizing patients to treatment with enalapril to replicate PARADIGM-HF trial results would not be ethical [64].

In PARADIGM-HF, sacubitril/valsartan was very well tolerated, and fewer patients taking sacubitril/valsartan discontinued study medication because of adverse effects compared with those taking enalapril [53]. Hypotension that required dose reduction was seen more often with sacubitril/valsartan, but renal dysfunction, hyperkalemia, and cough requiring discontinuation of study medication were more common with enalapril [66]. Few cases of angioedema were reported, with no significant difference between study groups [53]. Furthermore, in a meta-analysis of six hypertension and HF trials involving 11,821 patients, sacubitril/valsartan was associated with significantly lower risk of treatment discontinuation for any adverse event than was an ACEI/ARB or placebo [67]. Therefore, based on a critical examination of the available literature on sacubitril/valsartan, it is difficult to understand the reluctance of the AAFP to fully endorse the AHA/ACC/HFSA guideline recommendations to replace ACEI or ARB therapy with sacubitril/valsartan in patients with HFrEF.

The guideline update also offers two important safety recommendations with respect to the ARNI class: "ARNI should not be administered concomitantly with ACEIs or within 36 hours of the last dose of an ACEI" (COR III, LOE B-R) and "ARNI should not be administered to patients with a history of angioedema" (COR III, LOE C-EO) $[4,47]$. These safety recommendations address the potential risk for angioedema that was observed with omapatrilat (a dual neprilysin inhibitor/ACEI), which halted the clinical development of this drug $[60,68]$. The higher incidence of angioedema was because both pharmacodynamic effects of omapatrilat result in bradykinin accumulation. Because ARBs do not inhibit bradykinin degradation, the substitution of an ARB agent (such as valsartan) for the ACEI should mitigate the risk for angioedema. Indeed, the overall incidence of angioedema in the PARADIGM-HF trial was low and nonsignificant compared with enalapril (19 vs. $10 ; P=0.13$ ) [53]. It is also important to note that because one component of ARNI therapy is an ARB agent (i.e., valsartan in sacubitril/valsartan), ARNI should also not be used concomitantly with another ARB [69].

\section{Areas for Improvement in the Treatment of HF}

\subsection{Uptitration of Pharmacologic Therapies}

The ACCF/AHA guideline for the management of HF recommends uptitration of GDEM to the target or highesttolerated doses (Table 3) shown to improve outcomes in 
Table 3 Evidence-based doses of drugs commonly used for the treatment of HF [2]

\begin{tabular}{|c|c|c|}
\hline Drug & Starting dose, $\mathrm{mg}$ & Target dose, mg \\
\hline \multicolumn{3}{|l|}{ ACEIs } \\
\hline Captopril & $6.25 \mathrm{tid}$ & 50 tid \\
\hline Enalapril & $2.5 \mathrm{bid}$ & 10-20 bid \\
\hline Fosinopril $^{\mathrm{a}}$ & $5-10$ od & 40 od \\
\hline Lisinopril & $2.5-5.0 \mathrm{od}$ & $20-40$ od \\
\hline Perindopril $^{\mathrm{a}}$ & $2 \mathrm{od}$ & $8-16$ od \\
\hline Quinapril $^{\mathrm{a}}$ & 5 bid & 20 bid \\
\hline Ramipril $^{\mathrm{a}}$ & $1.25-2.5 \mathrm{od}$ & 10 od \\
\hline Trandolapril $^{\mathrm{a}}$ & $1 \mathrm{od}$ & $4 \mathrm{od}$ \\
\hline \multicolumn{3}{|l|}{$\mathrm{ARBs}$} \\
\hline Candesartan & $4-8$ od & $32 \mathrm{od}$ \\
\hline Losartan & $25-50$ od & $50-150$ od \\
\hline Valsartan & $20-40$ bid & 160 bid \\
\hline \multicolumn{3}{|l|}{ ARNI } \\
\hline Sacubitril/valsartan & 100 bid & 200 bid \\
\hline \multicolumn{3}{|l|}{ Aldosterone antagonists } \\
\hline Eplerenone & 25 od & 50 od \\
\hline Spironolactone & $12.5-25.0 \mathrm{od}$ & 25 od or bid \\
\hline \multicolumn{3}{|l|}{ Beta blockers } \\
\hline Bisoprolol & $1.25 \mathrm{od}$ & 10 od \\
\hline Carvedilol & $3.125 \mathrm{bid}$ & 50 bid \\
\hline Carvedilol $\mathrm{CR}^{\mathrm{a}}$ & 10 od & 80 od \\
\hline Metoprolol succinate $(\mathrm{CR} / \mathrm{XL})$ & $12.5-25.0 \mathrm{od}$ & $200 \mathrm{od}$ \\
\hline \multicolumn{3}{|l|}{ Hydralazine and isosorbide dinitrate } \\
\hline Fixed-dose combination & 37.5 hydralazine/20 isosorbide dinitrate tid & 75 hydralazine/40 isosorbide dinitrate tid \\
\hline
\end{tabular}

Doses are presented as $\mathrm{mg}$

$A C E I$ angiotensin-converting enzyme inhibitor, $A R B$ angiotensin receptor blocker, $A R N I$ angiotensin receptor-neprilysin inhibitor, bid twice daily, $C R$ controlled release, od once daily, tid three times daily, $X L$ extended release

${ }^{\text {a }}$ Suggested target doses were not studied in clinical trials

clinical trials [2]. Optimized GDEM for stage C HFrEF decreased the relative risk of mortality by $17-43 \%$ and the relative risk of $\mathrm{HF}$ hospitalization by $31-41 \%$ against the comparator arms in randomized controlled trials [2]. However, HF medication doses are not always escalated as directed [70, 71]. There are several possible reasons for this observation. One explanation may be that patients with HF are not seen often enough to allow for adjustments. Some physicians perceive that escalated doses of HF drugs may negatively affect patients or higher doses of ACEIs, ARBs, and aldosterone receptor antagonists may worsen renal function [2]. Thus, physicians may be hesitant to increase doses when renal function cannot be carefully monitored. However, considerable evidence suggests that despite mild worsening of renal function, uptitration of RAAS blockers and aldosterone antagonists is associated with better outcomes [72-74]. The development of hypotension may prevent uptitration due to concerns of advanced pump failure, but other causes of hypotension should be considered before adjusting HF medications. These other causes include overdiuresis, dehydration, acute coronary syndrome, ischemia, arrhythmia, autonomic dysfunction, gastrointestinal bleeding, infection, or use of drugs for conditions other than HF [75]. Typically, hypotension resolves spontaneously after diuretic dose reduction in euvolemic patients or after management of other medications and/or comorbidities [75]. Moreover, vasodilators such as RAAS blockers and the combination of hydralazine and isosorbide often improve blood pressure with continued use [76, 77]. Some physicians are concerned that intensification of beta-blocker therapy may lower cardiac output short term and worsen HF; however, the author is aware of no evidence to date that uptitration of betablockers is associated with hospitalization in the subsequent 30 days [70].

Interestingly, evidence suggests that patients having telephone consultations at 1- to 3-week intervals with registered nurses or cardiologists may efficiently optimize 
dose escalation of HF medication, improving clinical outcomes [78]. Analysis of data from the Train-the-Trainer trial also found that increasing the self-confidence of PCPs in treating $\mathrm{HF}$ by using educational interventions improved evidence-based prescription of RAAS blockers [79]. However, other studies do not support such interventions [80], and more studies are required to confirm these findings.

The GUIDE-IT (Guiding Evidence-based Therapy Using Biomarker Intensified Treatment in Heart Failure; NCT01685840) study aimed to assess whether natriuretic peptide (i.e., NT-proBNP)-guided treatment improved clinical outcomes versus usual care in high-risk patients with HFrEF [81]. The data and safety monitoring board recommended stopping the study when only 894 of the planned 1100 patients had been enrolled, with follow-up for a median of 15 months, because of futility [82]. The primary outcome of the composite of time-to-first HF hospitalization or death from cardiovascular causes occurred in 164 patients (37\%) in the biomarker-guided group and 164 patients (37\%) in the usual-care group [82]. None of the secondary endpoints, nor the decreases in the NT-proBNP levels achieved, differed significantly between groups [82]. Hence, the natriuretic peptide-guided strategy to uptitrate HF medications cannot be recommended. Additional research is necessary to improve implementation of evidence-based therapy into clinical practice. Meanwhile, physicians are encouraged to optimize guideline-recommended uptitration of HF medications.

\subsection{Switching Therapies}

As mentioned, previous guideline recommendations focused on stacking newer therapies on older approved drugs and have not considered it appropriate to switch a patient's existing pharmacologic regimen [83]. This is because all previous trials have compared the active drug on top of the standard of care against a placebo [84]. However, the PARADIGM-HF trial tested the ARNI sacubitril/valsartan against the active comparator ACEI enalapril and found it to be superior [84]. Hence, the guidelines recommend switching from ACEI/ARB therapy to ARNI therapy [47].

Unfortunately, physicians are often hesitant to even intensify therapies when patients appear to be stable and lack clinical evidence of progression [85]. Therefore, physicians may be even more diffident to switch to a new therapy in stable patients. Considerable efforts may be required to educate physicians about the benefits of switching from ACEI/ARB to ARNI therapy. In many cases, physicians may find it easier to implement new HF treatment strategies with new patients than to switch therapy in seemingly stable patients.
When considering a switch in medication, physicians should confirm that patients are receiving therapeutically appropriate doses of their current treatments and that aggressive efforts have been made to reach target doses (Table 3). Analysis of data from the IMPROVE-HF (Registry to Improve the Use of Evidence-based Heart Failure Therapies in the Outpatient Setting; NCT00303979) showed that, prior to implementation of a practice-based performance improvement intervention at outpatient cardiology clinics, only $36.1,20.5$, and $74.4 \%$ of patients were receiving recommended target doses of ACEIs/ARBs, beta-blockers, and aldosterone antagonists, respectively [86]. Similarly, data from the OPTIMIZE-HF (Organized Program to Initiate Lifesaving Treatment in Hospitalized Patients With Heart Failure; NCT00344513) indicated that target doses of the beta-blockers carvedilol and metoprolol succinate, used for 60-90 days after hospital discharge, were achieved only by 17.5 and $7.9 \%$ of patients, respectively [71].

\subsection{Improving Adherence}

Although GDEM is recommended to reduce the risk of disease progression, it is not always appropriately initiated in clinical practice. A survey of 1378 specialists in family medicine, internal medicine, and general cardiology found that referral practices for an ICD for primary prevention are often discordant with evidence-based guideline recommendations from the ACC/AHA/Heart Rhythm Society [83]. Survey results observed that $28 \%$ of respondents reported that they never refer patients for consideration of an ICD, $15 \%$ believed ventricular arrhythmia is required before an ICD is indicated, and 36\% believed an EF > 40\% warrants an ICD [83]. Of the respondents, the specialists most likely to give responses that were inconsistent with guideline recommendations were family practice physicians, as demonstrated by multivariate analyses of survey responses [83].

Similarly, telephone interviews with clinicians at US Department of Veterans Affairs healthcare systems found that many physicians believe HF guideline recommendations are less applicable in the very elderly (aged $>80$ years) and in those with multiple comorbidities that increase clinical complexity and risk of adverse medication effects [87]. Practitioners reported having concerns about the validity of evidence-based HF guideline recommendations in these higher-risk patient populations, despite evidence that these subgroups may receive greater absolute benefit from HF medications [87]. Correspondingly, findings from the HART (Heart Failure Adherence Retention Trial) showed that physicians are significantly less likely to follow evidence-based guideline recommendations for ACEIs/ARBs and beta-blockers-which include not 
prescribing therapy when contraindicated-in patients with multiple comorbidities, older patients, patients with higher NYHA class, and ethnic minorities [88].

\subsection{HF Management in Primary Care}

The quality of the PCP-patient relationship is essential for the optimal management of HF. To reduce the risk of poor outcomes, physicians must be able to identify the oftensubtle symptoms of WHF in seemingly stable patients [89]. Thus, physicians need to establish a trusting relationship with patients to whom they provide information about the progressive nature of HF along with reassurances to alleviate patient fears and concerns. Patients should feel comfortable having honest conversations with their PCPs and should feel confident that their providers are knowledgeable about HF. However, a recent study by Zickmund et al. [89] found that about three in ten patients expressed complaints about their physicians, including poor interpersonal skills, lack of confidence in their medical competence to diagnosis and treat congestive $\mathrm{HF}$, and inability to provide sufficient medical information. Therefore, initiatives are needed to train physicians in ways to improve the PCP-patient relationship [89]. To improve patient confidence, physicians should have strong knowledge of current HF guideline recommendations and stay abreast of new therapies and strategies to improve patient care.

PCPs should also collaborate with other healthcare professionals as part of a multidisciplinary network of care because team approaches that include input from cardiologists, nurses, pharmacists, physical therapists, dietitians, and PCPs have been shown to improve patient survival, decrease readmission rates, and improve patient quality of life [90, 91]. For example, Lee et al. [92] found that collaboration between a PCP and a cardiologist within 30 days of a patient's hospital discharge improved rates of follow-up testing, use of GDEM, and survival compared with PCP care alone. Moreover, multidisciplinary HF disease-management programs are recommended to facilitate the implementation of GDEM, prevent readmissions to hospital, and address barriers to behavior change (COR I, LOE B) [2].

\section{Conclusions}

Although HF management has considerably improved in the past several years, mortality rates remain high, with only about $50 \%$ of patients surviving more than 5 years after diagnosis [7]. Fortunately, recent clinical studies of ivabradine and sacubitril/valsartan suggest that, for the first time in more than a decade, patient outcomes for HF could be further improved. These new therapies were tested in patients with apparently stable HF, who often experience subclinical disease progression in the absence of symptoms or signs of decompensation. Data from these trials underscore the fact that the apparently stable patient with chronic HF remains at increased risk of asymptomatic progression of HF, death, and hospitalization. However, we now have new therapies that have been shown to be particularly beneficial for such patients.

In conclusion, physicians need to stay informed about advances in HF treatment and strive to improve HF management strategies for their patients. Early therapeutic intervention with aggressive uptitration of GDEM is important to reduce poor outcomes, and new therapies are likely to prevent disease progression. Physicians must also stay engaged with patients to identify subtle signs of disease progression and maintain an open dialogue with patients to ensure their needs are being met.

\section{Compliance with Ethical Standards}

Funding Technical assistance with editing and styling of the manuscript for submission was provided by Oxford PharmaGenesis Inc., Newtown, Pennsylvania, USA, and was funded by Novartis Pharmaceuticals Corporation, East Hanover, New Jersey, USA.

Conflict of interest The author was fully responsible for all content and editorial decisions and received no financial support or other form of compensation related to the development of this manuscript. Dr. Anand is a consultant to, and has received honoraria from, Amgen, Arca, AstraZeneca, Boehringer Ingelheim, Cyberonics, and Zensun.

Statement of human and animal rights This article does not contain any studies with human participants performed by the author.

Open Access This article is distributed under the terms of the Creative Commons Attribution-NonCommercial 4.0 International License (http://creativecommons.org/licenses/by-nc/4.0/), which permits any noncommercial use, distribution, and reproduction in any medium, provided you give appropriate credit to the original author(s) and the source, provide a link to the Creative Commons license, and indicate if changes were made.

\section{References}

1. Bui AL, Horwich TB, Fonarow GC. Epidemiology and risk profile of heart failure. Nat Rev Cardiol. 2011;8:30-41.

2. Yancy CW, Jessup M, Bozkurt B, Butler J, Casey DE Jr, Drazner $\mathrm{MH}$, et al. $2013 \mathrm{ACCF} / \mathrm{AHA}$ guideline for the management of heart failure: a report of the American College of Cardiology Foundation/American Heart Association Task Force on practice guidelines. Circulation. 2013;128:e240-319.

3. Loh JC, Creaser J, Rourke DA, Livingston N, Harrison TK, Vandenbogaart E, et al. Temporal trends in treatment and outcomes for advanced heart failure with reduced ejection fraction from 1993-2010: findings from a university referral center. Circ Heart Fail. 2013;6:411-9.

4. Yancy CW, Jessup M, Bozkurt B, Butler J, Casey DE Jr, Colvin MM, et al. 2016 ACC/AHA/HFSA focused update on new pharmacological therapy for heart failure: an update of the 2013 
$\mathrm{ACCF} / \mathrm{AHA}$ guideline for the management of heart failure: a report of the American College of Cardiology/American Heart Association Task Force on Clinical Practice Guidelines and the Heart Failure Society of America. J Am Coll Cardiol. 2016;68:1476-88.

5. Shah RU, Tsai V, Klein L, Heidenreich PA. Characteristics and outcomes of very elderly patients after first hospitalization for heart failure. Circ Heart Fail. 2011;4:301-7.

6. Centers for Medicare and Medicaid Services. Readmissions Reduction Program. https://www.cms.gov/medicare/medicarefee-for-service-payment/acuteinpatientpps/readmissions-reducti on-program.html. Accessed 2 Feb 2016.

7. Mozaffarian D, Benjamin EJ, Go AS, Arnett DK, Blaha MJ, Cushman M, et al. Heart disease and stroke statistics-2015 update: a report from the American Heart Association. Circulation. 2015;131:e29-322.

8. Heidenreich PA, Albert NM, Allen LA, Bluemke DA, Butler J, Fonarow GC, et al. Forecasting the impact of heart failure in the United States: a policy statement from the American Heart Association. Circ Heart Fail. 2013;6:606-19.

9. Muntwyler J, Abetel G, Gruner C, Follath F. One-year mortality among unselected outpatients with heart failure. Eur Heart J. 2002;23:1861-6.

10. Ponikowski P, Voors AA, Anker SD, Bueno H, Cleland JG, Coats AJ, et al. 2016 ESC Guidelines for the diagnosis and treatment of acute and chronic heart failure: The Task Force for the diagnosis and treatment of acute and chronic heart failure of the European Society of Cardiology (ESC). Developed with the special contribution of the Heart Failure Association (HFA) of the ESC. Eur J Heart Fail. 2016;18:891-975.

11. Owan TE, Hodge DO, Herges RM, Jacobsen SJ, Roger VL, Redfield MM. Trends in prevalence and outcome of heart failure with preserved ejection fraction. N Engl J Med. 2006;355:251-9.

12. Fonarow GC, Stough WG, Abraham WT, Albert NM, Gheorghiade $\mathrm{M}$, Greenberg $\mathrm{BH}$, et al. Characteristics, treatments, and outcomes of patients with preserved systolic function hospitalized for heart failure: a report from the OPTIMIZE-HF Registry. J Am Coll Cardiol. 2007;50:768-77.

13. Kostis JB, Davis BR, Cutler J, Grimm RH Jr, Berge KG, Cohen JD, et al. Prevention of heart failure by antihypertensive drug treatment in older persons with isolated systolic hypertension. SHEP Cooperative Research Group. JAMA. 1997;278:212-6.

14. Beckett NS, Peters R, Fletcher AE, Staessen JA, Liu L, Dumitrascu D, et al. Treatment of hypertension in patients 80 years of age or older. N Engl J Med. 2008;358:1887-98.

15. Sciarretta S, Palano F, Tocci G, Baldini R, Volpe M. Antihypertensive treatment and development of heart failure in hypertension: a Bayesian network meta-analysis of studies in patients with hypertension and high cardiovascular risk. Arch Intern Med. 2011;171:384-94.

16. Staessen JA, Wang JG, Thijs L. Cardiovascular prevention and blood pressure reduction: a quantitative overview updated until 1 March 2003. J Hypertens. 2003;21:1055-76.

17. Verdecchia P, Sleight P, Mancia G, Fagard R, Trimarco B, Schmieder RE, et al. Effects of telmisartan, ramipril, and their combination on left ventricular hypertrophy in individuals at high vascular risk in the Ongoing Telmisartan Alone and in Combination With Ramipril Global End Point Trial and the Telmisartan Randomized Assessment Study in ACE Intolerant Subjects With Cardiovascular Disease. Circulation. 2009;120:1380-9.

18. Taylor F, Ward K, Moore TH, Burke M, Davey Smith G, Casas JP, et al. Statins for the primary prevention of cardiovascular disease. Cochrane Database Syst Rev. 2011;1:CD004816. https:// doi.org/10.1002/14651858.cd004816.pub4.

19. Wilhelmsen L, Rosengren A, Eriksson H, Lappas G. Heart failure in the general population of men-morbidity, risk factors and prognosis. J Intern Med. 2001;249:253-61.
20. Butler J, Kalogeropoulos A, Georgiopoulou V, Belue R, Rodondi $\mathrm{N}$, Garcia M, et al. Incident heart failure prediction in the elderly: the health ABC heart failure score. Circ Heart Fail. 2008; 1:125-33.

21. Kalogeropoulos A, Georgiopoulou V, Harris TB, Kritchevsky SB, Bauer DC, Smith AL, et al. Glycemic status and incident heart failure in elderly without history of diabetes mellitus: the health, aging, and body composition study. J Card Fail. 2009;15:593-9.

22. Lind M, Bounias I, Olsson M, Gudbjornsdottir S, Svensson AM, Rosengren A. Glycaemic control and incidence of heart failure in 20,985 patients with type 1 diabetes: an observational study. Lancet. 2011;378:140-6.

23. Pfister R, Cairns R, Erdmann E, Schneider CA. A clinical risk score for heart failure in patients with type 2 diabetes and macrovascular disease: an analysis of the PROactive study. Int $\mathrm{J}$ Cardiol. 2013;162:112-6.

24. Køber L. Heart failure in 2015: better results from prevention than from additional treatment. Nat Rev Cardiol. 2016;13:75-7.

25. Zinman B, Wanner C, Lachin JM, Fitchett D, Bluhmki E, Hantel $\mathrm{S}$, et al. Empagliflozin, cardiovascular outcomes, and mortality in type 2 diabetes. N Engl J Med. 2015;373:2117-28.

26. Fitchett D, Zinman B, Wanner C, Lachin JM, Hantel S, Salsali A, et al. Heart failure outcomes with empagliflozin in patients with type 2 diabetes at high cardiovascular risk: results of the EMPAREG OUTCOME(R) trial. Eur Heart J. 2016;37:1526-34.

27. Yeboah J, Rodriguez CJ, Stacey B, Lima JA, Liu S, Carr JJ, et al. Prognosis of individuals with asymptomatic left ventricular systolic dysfunction in the multi-ethnic study of atherosclerosis (MESA). Circulation. 2012;126:2713-9.

28. SOLVD Investigators, Yusuf S, Pitt B, Davis CE, Hood WB Jr, Cohn JN. Effect of enalapril on mortality and the development of heart failure in asymptomatic patients with reduced left ventricular ejection fractions. N Engl J Med. 1992;327:685-91.

29. Ahn SA, Jong P, Yusuf S, Bangdiwala SI, Pouleur HG, Rousseau MF. Early versus delayed enalapril in patients with left ventricular systolic dysfunction: impact on morbidity and mortality 15 years after the SOLVD trial. J Am Coll Cardiol. 2006;47:1904-5.

30. Nudi F, Di Belardino N, Versaci F, Pinto A, Procaccini E, Neri G, et al. Impact of coronary revascularization vs medical therapy on ischemia among stable patients with or suspected coronary artery disease undergoing serial myocardial perfusion scintigraphy. J Nucl Cardiol. 2017;24:1690-8.

31. Nudi F, Procaccini E, Versaci F, Giordano A, Pinto A, Neri G, et al. Impact of coronary revascularization on the clinical and scintigraphic outlook of patients with myocardial ischemia. J Cardiovasc Med (Hagerstown). 2017;18:404-9.

32. Gheorghiade M, Hall VB, Jacobsen G, Alam M, Rosman H, Goldstein S. Effects of increasing maintenance dose of digoxin on left ventricular function and neurohormones in patients with chronic heart failure treated with diuretics and angiotensin-converting enzyme inhibitors. Circulation. 1995;92:1801-7.

33. Slatton ML, Irani WN, Hall SA, Marcoux LG, Page RL, Grayburn PA, et al. Does digoxin provide additional hemodynamic and autonomic benefit at higher doses in patients with mild to moderate heart failure and normal sinus rhythm? J Am Coll Cardiol. 1997;29:1206-13.

34. Fogelman AM, La Mont JT, Finkelstein S, Rado E, Pearce ML. Fallibility of plasma-digoxin in differentiating toxic from nontoxic patients. Lancet. 1971;2:727-9.

35. Ingelfinger JA, Goldman P. The serum digitalis concentrationdoes it diagnose digitalis toxicity? $\mathrm{N}$ Engl $\mathrm{J}$ Med. 1976;294:867-70.

36. Juurlink DN, Mamdani M, Kopp A, Laupacis A, Redelmeier DA. Drug-drug interactions among elderly patients hospitalized for drug toxicity. JAMA. 2003;289:1652-8. 
37. Hager WD, Fenster P, Mayersohn M, Perrier D, Graves P, Marcus FI, et al. Digoxin-quinidine interaction pharmacokinetic evaluation. N Engl J Med. 1979;300:1238-41.

38. Bizjak ED, Mauro VF. Digoxin-macrolide drug interaction. Ann Pharmacother. 1997;31:1077-9.

39. Steiner JF, Robbins LJ, Hammermeister KE, Roth SC, Hammond WS. Incidence of digoxin toxicity in outpatients. West J Med. 1994;161:474-8.

40. Packer M, O’Connor CM, Ghali JK, Pressler ML, Carson PE, Belkin RN, et al. Effect of amlodipine on morbidity and mortality in severe chronic heart failure. Prospective Randomized Amlodipine Survival Evaluation Study Group. N Engl J Med. 1996;335:1107-14.

41. Cohn JN, Ziesche S, Smith R, Anand I, Dunkman WB, Loeb H, et al. Effect of the calcium antagonist felodipine as supplementary vasodilator therapy in patients with chronic heart failure treated with enalapril: V-HeFT III. Vasodilator-Heart Failure Trial (V-HeFT) Study Group. Circulation. 1997;96:856-63.

42. Littler WA, Sheridan DJ. Placebo controlled trial of felodipine in patients with mild to moderate heart failure. UK Study Group. Br Heart J. 1995;73:428-33.

43. Udelson JE, DeAbate CA, Berk M, Neuberg G, Packer M, Vijay $\mathrm{NK}$, et al. Effects of amlodipine on exercise tolerance, quality of life, and left ventricular function in patients with heart failure from left ventricular systolic dysfunction. Am Heart $\mathrm{J}$. 2000;139:503-10.

44. Thackray S, Witte K, Clark AL, Cleland JG. Clinical trials update: OPTIME-CHF, PRAISE-2, ALL-HAT. Eur J Heart Fail. 2000;2:209-12.

45. Fonarow GC, Yancy CW, Hernandez AF, Peterson ED, Spertus JA, Heidenreich PA. Potential impact of optimal implementation of evidence-based heart failure therapies on mortality. Am Heart J. 2011;161(1024):1030.e3.

46. Fonarow GC, Hernandez AF, Solomon SD, Yancy CW. Potential mortality reduction with optimal implementation of angiotensin receptor neprilysin inhibitor therapy in heart failure. JAMA Cardiol. 2016;1:714-7.

47. Yancy CW, Jessup M, Bozkurt B, Butler J, Casey DE Jr, Colvin MM, et al. 2017 ACC/AHA/HFSA focused update of the 2013 ACCF/AHA Guideline for the Management of Heart Failure: a Report of the American College of Cardiology/American Heart Association Task Force on Clinical Practice Guidelines and the Heart Failure Society of America. J Card Fail. 2017;23:628-51.

48. Kemp CD, Conte JV. The pathophysiology of heart failure. Cardiovasc Pathol. 2012;21:365-71.

49. Latini R, Masson S, Anand IS, Missov E, Carlson M, Vago T, et al. Prognostic value of very low plasma concentrations of troponin $\mathrm{T}$ in patients with stable chronic heart failure. Circulation. 2007;116:1242-9.

50. Alehagen U, Dahlström U, Rehfeld JF, Goetze JP. Prognostic assessment of elderly patients with symptoms of heart failure by combining high-sensitivity troponin $\mathrm{T}$ and $\mathrm{N}$-terminal pro-B-type natriuretic peptide measurements. Clin Chem. 2010;56:1718-24.

51. Marti CN, Gheorghiade M, Kalogeropoulos AP, Georgiopoulou VV, Quyyumi AA, Butler J. Endothelial dysfunction, arterial stiffness, and heart failure. J Am Coll Cardiol. 2012;60:1455-69.

52. Anker SD, Sharma R. The syndrome of cardiac cachexia. Int $\mathbf{J}$ Cardiol. 2002;85:51-66.

53. McMurray JJ, Packer M, Desai AS, Gong J, Lefkowitz MP, Rizkala AR, et al. Angiotensin-neprilysin inhibition versus enalapril in heart failure. N Engl J Med. 2014;371:993-1004.

54. United States Food and Drug Administration, Center for Drug Evaluation and Research. Corlanor NDA 206143 [approval letter]; April 15, 2015. https://www.accessdata.fda.gov/drugsatfda docs/nda/2015/206143Orig1s000Approv.pdf. Accessed 10 Oct 2017.
55. United States Food and Drug Administration, Center for Drug Evaluation and Research. Entresto NDA 207620 [approval letter]; July 7, 2015. https://www.accessdata.fda.gov/drugsatfda_ docs/appletter/2015/207620Orig1s000ltr.pdf. Accessed 10 Oct 2017.

56. Corlanor (ivabradine) tablets [prescribing information]. Thousand Oaks: Amgen, Inc.; 2015.

57. Swedberg K, Komajda M, Böhm M, Borer JS, Ford I, DubostBrama A, et al. Ivabradine and outcomes in chronic heart failure (SHIFT): a randomised placebo-controlled study. Lancet. 2010;376:875-85.

58. Gu J, Noe A, Chandra P, Al-Fayoumi S, Ligueros-Saylan M, Sarangapani R, et al. Pharmacokinetics and pharmacodynamics of LCZ696, a novel dual-acting angiotensin receptor-neprilysin inhibitor (ARNi). J Clin Pharmacol. 2010;50:401-14.

59. McMurray JJ. Neprilysin inhibition to treat heart failure: a tale of science, serendipity, and second chances. Eur J Heart Fail. 2015;17:242-7.

60. Braunwald E. The path to an angiotensin receptor antagonistneprilysin inhibitor in the treatment of heart failure. J Am Coll Cardiol. 2015;65:1029-41.

61. Desai AS, McMurray JJ, Packer M, Swedberg K, Rouleau JL, Chen F, et al. Effect of the angiotensin-receptor-neprilysin inhibitor LCZ696 compared with enalapril on mode of death in heart failure patients. Eur Heart J. 2015;36:1990-7.

62. Packer M, McMurray JJ, Desai AS, Gong J, Lefkowitz MP, Rizkala AR, et al. Angiotensin receptor neprilysin inhibition compared with enalapril on the risk of clinical progression in surviving patients with heart failure. Circulation. 2015;131:54-61.

63. Chavey WE, Hogikyan RV, Van Harrison R, Nicklas JM. Heart failure due to reduced ejection fraction: medical management. Am Fam Physician. 2017;95:13-20.

64. Packer M. Kicking the tyres of a heart failure trial: physician response to the approval of sacubitril/valsartan in the USA. Eur J Heart Fail. 2016;18:1211-9.

65. Kristensen SL, Martinez F, Jhund PS, Arango JL, Bělohlávek J, Boytsov S, et al. Geographic variations in the PARADIGM-HF heart failure trial. Eur Heart J. 2016;37:3167-74.

66. Vardeny O, Claggett B, Packer M, Zile MR, Rouleau J, Swedberg $\mathrm{K}$, et al. Efficacy of sacubitril/valsartan vs. enalapril at lower than target doses in heart failure with reduced ejection fraction: the PARADIGM-HF trial. Eur J Heart Fail. 2016;18:1228-34.

67. Li B, Zhao Y, Yin B, Helian M, Wang X, Chen F, et al. Safety of the neprilysin/renin-angiotensin system inhibitor LCZ696. Oncotarget. 2017;8:83323-33.

68. Kostis JB, Packer M, Black HR, Schmieder R, Henry D, Levy E. Omapatrilat and enalapril in patients with hypertension: the Omapatrilat Cardiovascular Treatment vs. Enalapril (OCTAVE) trial. Am J Hypertens. 2004;17:103-11.

69. Entresto (sacubitril and valsartan) [prescribing information]. East Hanover: Novartis Pharmaceuticals Corporation; 2015.

70. Allen LA, Magid DJ, Zeng C, Peterson PN, Clarke CL, Shetterly $\mathrm{S}$, et al. Patterns of beta-blocker intensification in ambulatory heart failure patients and short-term association with hospitalization. BMC Cardiovasc Disord. 2012;12:43.

71. Fonarow GC, Abraham WT, Albert NM, Stough WG, Gheorghiade M, Greenberg BH, et al. Dosing of beta-blocker therapy before, during, and after hospitalization for heart failure (from Organized Program to Initiate Lifesaving Treatment in Hospitalized Patients with Heart Failure). Am J Cardiol. 2008;102:1524-9.

72. Jose P, Skali H, Anavekar N, Tomson C, Krumholz HM, Rouleau $\mathrm{JL}$, et al. Increase in creatinine and cardiovascular risk in patients with systolic dysfunction after myocardial infarction. J Am Soc Nephrol. 2006; 17:2886-91. 
73. Anand IS, Bishu K, Rector TS, Ishani A, Kuskowski MA, Cohn JN. Proteinuria, chronic kidney disease, and the effect of an angiotensin receptor blocker in addition to an angiotensin-converting enzyme inhibitor in patients with moderate to severe heart failure. Circulation. 2009;120:1577-84.

74. Vardeny O, Wu DH, Desai A, Rossignol P, Zannad F, Pitt B, et al. Influence of baseline and worsening renal function on efficacy of spironolactone in patients With severe heart failure: insights from RALES (Randomized Aldactone Evaluation Study). J Am Coll Cardiol. 2012;60:2082-9.

75. Bozkurt B. Response to Ryan and Parwani: heart failure patients with low blood pressure: how should we manage neurohormonal blocking drugs? Circ Heart Fail. 2012;5:820-1.

76. Anand IS, Tam SW, Rector TS, Taylor AL, Sabolinski ML, Archambault WT, et al. Influence of blood pressure on the effectiveness of a fixed-dose combination of isosorbide dinitrate and hydralazine in the African-American Heart Failure Trial. J Am Coll Cardiol. 2007;49:32-9.

77. Anand IS, Rector TS, Kuskowski M, Thomas S, Holwerda NJ, Cohn JN. Effect of baseline and changes in systolic blood pressure over time on the effectiveness of valsartan in the Valsartan Heart Failure Trial. Circ Heart Fail. 2008;1:34-42.

78. Steckler AE, Bishu K, Wassif H, Sigurdsson G, Wagner J, Jaenicke $\mathrm{C}$, et al. Telephone titration of heart failure medications. J Cardiovasc Nurs. 2011;26:29-36.

79. Peters-Klimm F, Laux G, Campbell S, Müller-Tasch T, Lossnitzer N, Schultz JH, et al. Physician and patient predictors of evidence-based prescribing in heart failure: a multilevel study. PLoS One. 2012;7:e31082.

80. Ong MK, Romano PS, Edgington S, Aronow HU, Auerbach AD, Black JT, et al. Effectiveness of remote patient monitoring after discharge of hospitalized patients with heart failure: The Better Effectiveness After Transition-Heart Failure (BEAT-HF) Randomized Clinical Trial. JAMA Intern Med. 2016;176:310-8.

81. Felker GM, Ahmad T, Anstrom KJ, Adams KF, Cooper LS, Ezekowitz JA, et al. Rationale and design of the GUIDE-IT study: guiding evidence based therapy using biomarker intensified treatment in heart failure. JACC Heart Fail. 2014;2:457-65.

82. Felker GM, Anstrom KJ, Adams KF, Ezekowitz JA, Fiuzat M, Houston-Miller $\mathrm{N}$, et al. Effect of natriuretic peptide-guided therapy on hospitalization or cardiovascular mortality in high-risk patients with heart failure and reduced ejection fraction: a randomized clinical trial. JAMA. 2017;318:713-20.
83. Castellanos JM, Smith LM, Varosy PD, Dehlendorf C, Marcus GM. Referring physicians' discordance with the primary prevention implantable cardioverter-defibrillator guidelines: a national survey. Heart Rhythm. 2012;9:874-81.

84. McMurray JJ, Packer M, Desai AS, Gong J, Lefkowitz M, Rizkala AR, et al. Baseline characteristics and treatment of patients in prospective comparison of ARNI with ACEI to determine impact on global mortality and morbidity in heart failure trial (PARADIGM-HF). Eur J Heart Fail. 2014;16:817-25.

85. Swennen MH, Rutten FH, Kalkman CJ, van der Graaf Y, Sachs AP, van der Heijden GJ. Do general practitioners follow treatment recommendations from guidelines in their decisions on heart failure management? A cross-sectional study. BMJ Open. 2013;3:e002982.

86. Gheorghiade M, Albert NM, Curtis AB, Thomas Heywood J, McBride ML, Inge PJ, et al. Medication dosing in outpatients with heart failure after implementation of a practice-based performance improvement intervention: findings from IMPROVE HF. Congest Heart Fail. 2012;18:9-17.

87. Steinman MA, Sudore RL, Peterson CA, Harlow JB, Fried TR. Influence of patient age and comorbid burden on clinician attitudes toward heart failure guidelines. Am J Geriatr Pharmacother. 2012;10:211-8.

88. Calvin JE, Shanbhag S, Avery E, Kane J, Richardson D, Powell L. Adherence to evidence-based guidelines for heart failure in physicians and their patients: lessons from the Heart Failure Adherence Retention Trial (HART). Congest Heart Fail. 2012;18:73-8.

89. Zickmund SL, Blasiole JA, Brase V, Arnold RM. Congestive heart failure patients report conflict with their physicians. J Card Fail. 2006;12:546-53.

90. Koshman SL, Charrois TL, Simpson SH, McAlister FA, Tsuyuki RT. Pharmacist care of patients with heart failure: a systematic review of randomized trials. Arch Intern Med. 2008;168:687-94.

91. Bonarek-Hessamfar M, Benchimol D, Lauribe P, Hadjo A, Matis $\mathrm{P}$, Dartigues JF, et al. Multidisciplinary network in heart failure management in a community-based population: results and benefits at 2 years. Int J Cardiol. 2009;134:120-2.

92. Lee DS, Stukel TA, Austin PC, Alter DA, Schull MJ, You JJ, et al. Improved outcomes with early collaborative care of ambulatory heart failure patients discharged from the emergency department. Circulation. 2010;122:1806-14. 